Research Article

\title{
Effects of Light and Nutrition Manipulations on Thermal Respiratory Acclimation and Nocturnal Dynamics of Leaf Dark Respiration
}

\author{
Dylan N. Dillaway, ${ }^{1,2}$ Michael C. Tyree ${ }^{1 D},{ }^{1,3}$ and John K. Jackson ${ }^{1}$ \\ ${ }^{1}$ Work Performed: School of Forestry, Louisiana Tech University, Ruston, LA 71272, USA \\ ${ }^{2}$ Center for Natural Resources Mgmt. \& Protection, Unity College, Unity, ME 04988, USA \\ ${ }^{3}$ Department of Biology, Indiana University of Pennsylvania, Indiana, PA 15705-1001, USA
}

Correspondence should be addressed to Michael C. Tyree; mtyree@iup.edu

Received 11 July 2018; Accepted 15 November 2018; Published 2 December 2018

Academic Editor: Yong In Kuk

Copyright $\odot 2018$ Dylan N. Dillaway et al. This is an open access article distributed under the Creative Commons Attribution License, which permits unrestricted use, distribution, and reproduction in any medium, provided the original work is properly cited.

The ability of a plant to acclimate metabolically to thermal changes is necessary to maintain a positive carbon balance. It is likely that a plant's acclimatory potential is a function of leaf nitrogen and/or leaf carbohydrate status. Two important issues assessed concerning leaf dark respiration $\left(R_{\mathrm{D}}\right)$ were the effects of growth temperature, light, and fertilization on thermal respiratory acclimation and changes in respiratory parameters (indicative of acclimation) throughout the dark period. Soybean (Glycine max (L.) Merr.) plants were grown in greenhouses under a full factorial treatment arrangement of temperature, light, and nutrition. $R_{\mathrm{D}}$ was measured at three temperatures to estimate respiratory parameters (cool respiration $R_{13}$, warm respiration $R_{25}$, and the temperature response of respiration $\left.E_{\mathrm{O}}\right)$ three times throughout the night $(6 \mathrm{pm}, 11 \mathrm{pm}$, and $4 \mathrm{am})$. Respiratory parameters did not differ throughout the night. Thermal acclimation was observed in warm grown plants under optimal growing conditions (i.e., high light and high fertilization); however, acclimation did not occur when limitations were imposed (i.e., shade or no fertilization). These findings suggest thermal acclimation will occur so long as plants do not undergo limitations. This may have major implications for natural ecosystems and may play a role in assessing an ecosystems resiliency to climate change.

\section{Introduction}

Tissue dark respiration $\left(R_{\mathrm{D}}\right)$ not only provides energy and carbon (C) skeletons for most plant metabolic processes [1] but also accounts for up to $50 \%$ of gross productivity [2]. Climate clearly exerts a strong influence on plant $\mathrm{C}$ balance as a whole, and this impact on tissue $R_{\mathrm{D}}$ is an important determinant of that balance being positive or negative [2]. In the short term, $R_{\mathrm{D}}$ has been shown to be quite sensitive to variations in temperature [3]; however, respiratory metabolism is often adjusted to minimize acceleration of $\mathrm{C}$ loss at higher temperatures [4]. The opposite effect has been observed when plants are exposed to low or declining temperatures [5], and the absence of thermal acclimation has been reported in other studies [6]. Clearly, the nature and extent of thermal $R_{\mathrm{D}}$ acclimation appear to differ significantly across species and growth environments [7-12]. When thermal acclimation is detected, it may be a result of changes in $R_{\mathrm{D}}$ at a predetermined base or cool temperature $[10,13]$, changes in the temperature response [7], or both [14].

Exponential functions are commonly used to describe the relationship between temperature and $R_{\mathrm{D}}$. However when measured over a range of short-term temperature changes, $Q_{10}$ (quantifying the relative rise in $R_{\mathrm{D}}$ with a $10^{\circ} \mathrm{C}$ increase in temperature) has been shown to introduce bias into these estimates [15], which can be avoided by using a modified Arrhenius equation to calculate an energy of activation $\left(E_{\mathrm{O}}\right)$ [16]. While both $Q_{10}$ and $E_{\mathrm{O}}$ values can range widely across tissue types, species, and environments, they are frequently large enough to result in at least a doubling of $R_{\mathrm{D}}$ with a $10^{\circ} \mathrm{C}$ increase in temperature [17]. Some studies have indicated correlations between this observed temperature response and leaf chemical traits [18]; however, there are a number of studies which have suggested that the 
mechanisms underlying $R_{\mathrm{D}}$ may differ at warmer versus cooler growth temperatures, and as a result, $E_{\mathrm{O}}$ (shape of temperature response curve) will be a function of these rates [4, 17]. For example, Dillaway and Kruger [19] reported a strong correlation between warm respiration $\left(R_{30}\right.$; respiration at $30^{\circ} \mathrm{C}$ ) and mass-based photosynthesis, while cool respiration (i.e., $20^{\circ} \mathrm{C}$ ) appeared to be a function of leaf nitrogen concentration $([N])$. Thus, when assessing the relationships between leaf traits and respiratory temperature response, it is imperative that both cool and warm respiration (minimum of $10^{\circ} \mathrm{C}$ temperature spread) are assessed equally but separately.

Studies which assess the respiratory response of plant tissues typically do not account for changes in respiration rates and or the temperature response of respiration throughout the nocturnal period [7, 14, 19-25]. Cumulative night-time respiration is often calculated using the temperature response of respiration measured at one point-in-time (usually just after sunset or just prior to sunrise) [19]. However, it is unknown whether this temperature response of respiration at the onset of darkness is in fact identical to the temperature response of respiration found at the conclusion of the nocturnal period $[26,27]$. One theory proposed to explain the observed differences in the temperature response of respiration across climate gradation is changes in $[N][2,28,29]$. However, none of the previously correlated variables can explain why the temperature response of respiration might change either throughout the night or as a result of longer-term adjustments to growth temperature (i.e., thermal acclimation). Given that leaf $[N]$ should be a relatively stable leaf chemical property (at least in the short-term), if a differential decline in respiration rates at contrasting temperature regimes is observed throughout the night, it should result mainly from changes in warm respiration indicating that this decline may be driven by carbohydrate concentration in the leaf.

This research addresses three important and related issues concerning leaf dark respiration:

(i) We assessed the effects of growth temperature, light, and fertilization on the temperature response of respiration and thus respiratory thermal acclimation. Thermal acclimation of respiration depends in large part on two important respiratory parameters including base respiration (cool respiration) and the temperature response of respiration $\left(E_{\mathrm{O}}\right.$, analogous to $Q_{10}$ ) $[4,17]$. For the purpose of this study, we adopted the theoretical construct of Atkin and Tjoelker [4] in which two types of acclimations are possible (Type I and Type II). Type I is theorized to be a result of a shift in the temperature response of $R_{D}$ (i.e., $Q_{10}$ or $E_{\mathrm{O}}$ ), and Type II is theorized to be a result of a shift in $R_{\mathrm{D}}$ at low temperatures (i.e., cool respiration $\left(R_{13}\right.$ in our study)). Based on current research, additional insight regarding the mechanistic underpinnings driving shifts in these variables is needed. We hypothesized that $E_{\mathrm{O}}$ would decrease with increased growth temperature due to a decline in warm respiration $\left(R_{25}\right)$. Cool respiration $\left(R_{13}\right)$ will not change as a result of growth temperature. (ii) We assessed the temporal temperature response of respiration throughout the dark period. Cumulative night-time respiration and the nature of thermal acclimatory adjustments cannot be predicted with a high level of confidence, to date. It is unknown whether these variables change throughout the dark period of a 24-hour span. We hypothesize that $E_{\mathrm{O}}$ and $R_{25}$ will decline throughout the night regardless of treatment but the decline will be more pronounced in the "warm" grown plants owing to faster depletion of carbohydrate stores. $R_{13}$ will remain stable throughout the night due to its strong correlation with leaf $[N]$.

(iii) Another principal goal of this research is to understand the fundamental mechanistic underpinnings of leaf dark respiration (warm respiration, cool respiration, and the temperature response of respiration) through manipulations of leaf carbohydrate concentration and leaf $[N]$ status of plants growing at contrasting growth temperatures. In this regard, we hypothesized that $E_{\mathrm{O}}$ and $R_{25}$ will be lower in the low-light treatments due to their positive correlation with total leaf nonstructural carbohydrate (TNC), while $R_{13}$ will be nonresponsive to light treatments due to its lack of correlation with leaf TNC. Because of the strong relationship between leaf $[N]$ and cool respiration $\left(R_{13}\right)$, the no fertilization treatment will exhibit a lower $R_{13}$ relative to the fertilization treatment; however, fertilization will show no apparent effect on $R_{25}$ or $E_{\mathrm{O}}$.

\section{Materials and Methods}

2.1. Study Design and Treatments. This work was conducted using university greenhouses located at Louisiana Tech University in Ruston, LA, from February to March 2010. This study employed a randomized complete block design replicated three times with the treatments arranged as a full $2 \times 2 \times 2$ factorial. Soybean (Glycine max (L.) Merr.) seeds were sown on 23 February 2010, in $4.4 \mathrm{~L}$ pots filled with a uniform soil mixture (Metro mix-300, Sun-gro horticulture, Bellevue, Washington). Seeds were germinated in a common greenhouse under ambient $\mathrm{CO}_{2}$ and a constant temperature of $23^{\circ} \mathrm{C}$ for approximately two weeks prior to treatment initiation.

Fertilizer and growth temperature treatments were initiated on 8 Mar. 2010. Seedlings were randomly moved to one of four greenhouses. Two houses were designated "warm" houses and maintained at a day/night temperature of $30 / 23^{\circ} \mathrm{C}$, while two houses were designated "cool" houses and maintained at a day/night temperature of $20 / 13^{\circ} \mathrm{C}$, resulting in a $\sim 10^{\circ} \mathrm{C}$ spread in temperature both during the day and night periods. Duplicate houses were used for each growth temperature treatment to ensure any responses were an effect of our treatments and not random differences among greenhouses. Half of all seedlings within each house were fertilized with a controlled release fertilizer (Osmocote, 15-9-12, Scott's, Marysville, OH). In each house, fertilized 
(F) and nonfertilized (NF) seedlings were grown under high light conditions. Soybean plants were grown for an additional two weeks after transitioning seedlings to treatment rooms in order to allow plants to fully acclimate to their new growth conditions and develop new foliage under their respective temperature regime. Shade treatments were initiated the morning prior to respiration measurements. Plants were shaded for approximately 14 hours prior to respiration measurement. During each measurement period, a subset of high light plants was moved into a shade house. Shade houses provided approximately 30\% of full sunlight and were designed to reduce daily $\mathrm{C}$ fixation of "low-light" plants relative to "high-light" plants (LL and HL, respectively).

2.2. Respiration Measurements. Respiration measurements were conducted for three consecutive days (23rd, 24th, and 25th Mar.). During each measurement period, nocturnal measurements were taken three times (beginning at 1800, 2300 , and $0400 \mathrm{~h}$ ) in order to examine the variability in key respiratory parameters throughout the night. Leaf dark respiration and its response to temperature were measured, for each treatment, during three "campaigns" throughout the night, using a Li-Cor 6400 portable photosynthesis machine (Li-Cor Biosciences, Lincoln, NE) with a $6 \mathrm{~cm}^{2}$ cuvette. Dark respiration $\left(R_{\mathrm{D}}\right)$ was determined on the youngest, fully expanded leaf from six plants per treatment, at three cuvette temperatures $\left(13^{\circ}, 18^{\circ}\right.$, and $\left.23^{\circ} \mathrm{C}\right)$. Partial pressure of $\mathrm{CO}_{2}$ $\left(p \mathrm{CO}_{2}\right)$ inside the cuvette reference chamber was maintained at $400 \mathrm{ppm}(\sim 40 \mathrm{~Pa})$ using the $\mathrm{CO}_{2}$ mixer on the Li-Cor 6400 . As in recent studies of leaf gas exchange $[19,30]$, we included a correction factor recommended by Pons and Welschen [31] in order to account for the "gasket effect" of commercially available photosynthesis systems.

The response of $R_{\mathrm{D}}$ to temperature was calculated using a modified Arrhenius equation [16, 18, 28]. The Arrhenius equation was chosen (as opposed to the $Q_{10}$ approach) so that estimates were not dependent on measurement temperature. The use of the Arrhenius equation allows us to calculate $R_{\mathrm{D}}$ for a particular leaf (with its unique $E_{\mathrm{O}}$ and temperature-adjusted $R_{\mathrm{D}}$ ) at any temperature of interest. Respiratory responses to growth environments were examined using several calculated parameters, including temperature-adjusted rates (Respiration at $25^{\circ} \mathrm{C}\left(R_{25}\right)$ and respiration at $13^{\circ} \mathrm{C}\left(R_{13}\right)$ ), along with the temperature response of respiration $\left(E_{\mathrm{O}}\right)$. Respiration rates at temperatures as low as or lower than $15^{\circ} \mathrm{C}$ are commonly used to assess "cool" respiratory metabolism in studies of $R_{\mathrm{D}}$ acclimation $[4,10,18]$.

2.3. Leaf Morphology and Chemistry. At the conclusion of each respiration campaign, all measured leaves were harvested, their projected leaf areas determined, and placed in a $70^{\circ} \mathrm{C}$ oven. After 72 hours, the leaves were removed from the oven and weighed. Leaf area and dry mass were used to calculate specific leaf area (SLA), which was used to convert leaf $R_{\mathrm{D}}$ to a mass basis $\left(\mathrm{nmol} \mathrm{g} \mathrm{g}^{-1} \cdot \mathrm{s}^{-1}\right)$. Leaves were then ground to a fine-powder and sent for $\mathrm{C}$ and $\mathrm{N}$ analysis (Brookside Laboratories, Ohio).
An additional set of leaves, proximal to (and serving as a proxy for) those measured for $R_{\mathrm{D}}$, were harvested simultaneously with individual $R_{\mathrm{D}}$ measurement campaigns. These samples were immediately frozen in a $-20^{\circ} \mathrm{C}$ freezer. Leaves were then freeze-dried using a benchtop lyophilizer (VirTis Bench Top, SP Industries Inc., NY), ground to a finepowder with a mortar and pestle, and analyzed for concentrations of total nonstructural carbohydrate (TNC) and its components (starch and soluble sugars), employing enzyme digestion and colorimetric assays similar to those detailed in Kaelke et al. [32]. Leaf starch and leaf [N] were then regressed against respiratory parameters (i.e., $R_{25}, E_{\mathrm{O}}$, and $R_{13}$ ) in order to determine the variables driving changes in the temperature response of respiration and temperatureadjusted rates of respiration.

2.4. Data Analyses. Determination of respiratory thermal acclimation was analyzed using analysis of variance with repeated measures where block, growth temperature, light, and fertilization main effects and interactions were treated as fixed effects. Time of night and all associated interaction terms were treated as random effects. All subsamples were averaged and assumptions checked using plots of normality curves and residuals prior to statistical analysis. For regression analysis, outlier observations were identified using Cook's distance procedure and removed when appropriate. All analyses were conducted using PROC MIXED and PROC REG in SAS 9.3 [33].

\section{Results}

3.1. Comparisons of Leaf Respiration at Common Temperatures. Estimates of $R_{\mathrm{D}}$ at a common temperature were calculated for cool metabolism and warm metabolism $\left(R_{13}\right.$ and $\left.R_{25}\right) . R_{25}$ was higher in the cool treatment under high light regardless of the associated fertilization treatment (Figure 1(c)).

Under low light, $R_{25}$ was not significantly different from the "warm" grown plants under either fertilization treatment (Figure $1(\mathrm{c})) . R_{13}$ in "cool" grown plants was higher than "warm" grown plants only in the high light, fertilized (HL,F) treatment but did not appear to vary under other combinations of light and fertilization (either low light or low nutrition) (Figure 1(b)). Within temperature regimes, $R_{13}$ in "warm" grown plants was unaffected by light and nutrition manipulations $\left(P=0.21\right.$ and $P=0.66$, respectively). $R_{25}$ in "warm" grown plants did not differ within HL or LL, but both HL,F and HL,NF were higher than their LL counterparts $(P=0.02$ and $P=0.07$, respectively) (Figure $1(\mathrm{c})$ ). Within "cool" grown plants, $R_{13}$ was significantly higher in the HL,F combination than all other light and fertilization combinations $(P \leq 0.05) . R_{25}$ in "cool" grown plants was significantly higher in the HL,F combination than the HL,NF plants $(P=0.01)$. Both the $\mathrm{F}$ and NF plants under HL were significantly greater $(P<0.0001$ and $P=0.002$, respectively) than their LL counterparts. $R_{25}$ showed no difference between the LL,F and LL,NF plants $(P=0.51$; Figure 1(c)). 


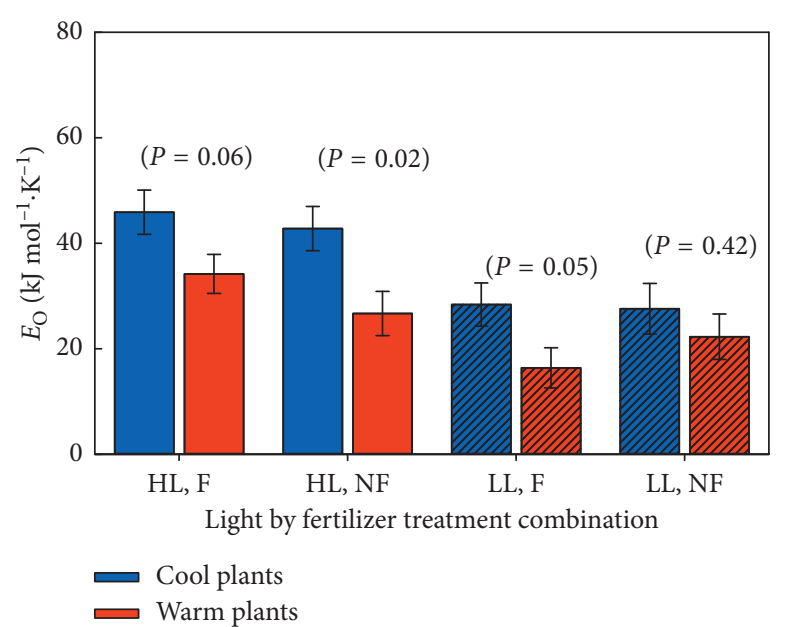

(a)

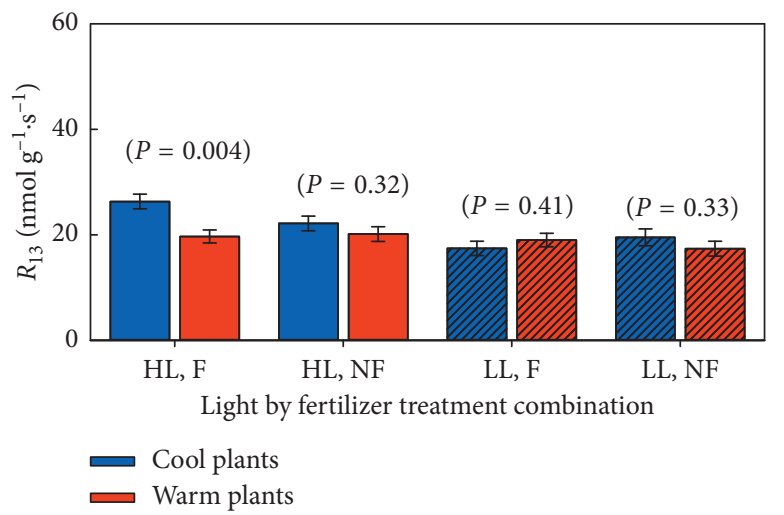

(b)

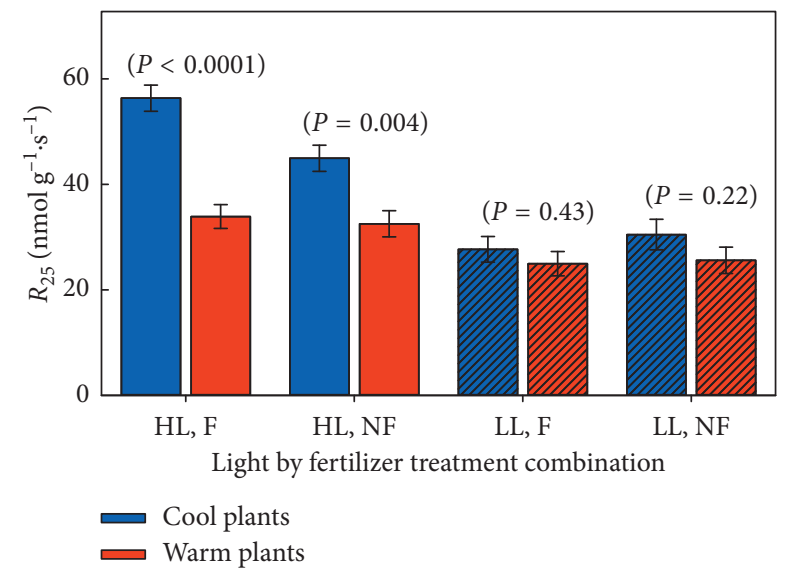

(c)

Figure 1: Differences among resource manipulation treatments for "warm" and "cool" grown plants (red and blue bars, respectively) for temperature response of respiration $\left(E_{\mathrm{O}}\right)(\mathrm{a})$, cool respiration $\left(R_{13}\right)(\mathrm{b})$, and warm respiration $\left(R_{25}\right)(\mathrm{c})$. Bars represent least square means $(n=18)$ throughout the night (error bars represent \pm one standard error from the mean). $P$ values show comparisons among "warm" and "cool" grown plants for each light (high light $=\mathrm{HL}$ and low light $=\mathrm{LL})$ by fertilization $(\mathrm{F}=$ fertilized and $\mathrm{NF}=$ no fertilizer added $)$ treatment combinations.

3.2. Temperature Sensitivity of Leaf Respiration. The temperature sensitivity of respiration $\left(E_{\mathrm{O}}\right)$ was significantly increased in "cool" grown plants relative to "warm" grown plants in all treatments with the exception of the LL,NF treatment (Figure 1(a)). Within the "cool" grown plants, $E_{\mathrm{O}}$ was significantly greater in the HL treatments than the LL treatments, regardless of the associated fertilization treatment $(P=0.002)$. Within the "warm" grown plants, there was no significant difference among any light-fertilization combinations with the exception of HL,F plants being greater than LL,F $(P=0.01)$.

3.3. Temporal Dynamics of Leaf Respiration and Leaf Carbohydrate. Throughout the night, we observed no significant change in $R_{13}, R_{25}$, or $E_{\mathrm{O}}$ in any treatment combination or temperature environment (Table 1 ). In addition, leaf starch, leaf soluble carbohydrate (TSC), and leaf total nonstructural carbohydrate (TNC) did not differ throughout the night (Table 1).
3.4. Leaf Carbohydrate Concentration. Leaf carbohydrate concentration (both starch and soluble carbohydrates) was affected by our treatments (Figure 2). Fertilization had the greatest effect on both starch $(P=0.01)$ and soluble carbohydrate $(P<0.0001)$ (Table 1$)$. Temperature and light also had a significant effect on starch $(P=0.03$ and $P=0.06$, respectively) and soluble carbohydrates $(P=0.02$ and $P=$ 0.01 , respectively). We did not, however, find any interactions between light, temperature, and fertilization with the exception of starch which showed an interaction between temperature and fertilization $(P=0.01$; Table 1$)$.

3.5. Leaf Nitrogen Concentration. Leaf $[N]$ did not differ among fertilized plants between "cool" and "warm" grown plants in either HL or LL (Table 2). However, we did find significant differences in leaf $[N]$ between "cool" and "warm" grown plants under $\operatorname{HL}(P=0.04)$ and $\operatorname{LL}(P=0.01)$. Lowest leaf $[N]$ concentrations occurred in the HL,NF in the "warm" grown plants. 
TABle 1: Partial $P$ table for leaf respiratory parameters (temperature response of respiration $\left(E_{\mathrm{O}}\right)$, basal respiration $\left(R_{13}\right)$, and warm respiration $\left(R_{25}\right)$ ) and leaf nonstructural C for "warm" and "cool" grown Glycine max (soybean) plants subjected to a factorial combination of light (L) and fertilization (F). Data were analyzed as a RCB design with treatments arranged as a full $2 \times 2 \times 2$ factorial measured repeatedly throughout the night using the repeated statement in PROC MIXED (SAS 9.3).

\begin{tabular}{lccccccc}
\hline & Num. & Den. & \multicolumn{3}{c}{ Resp. parameters } & \multicolumn{2}{c}{ Nonstructural C } \\
& $d f$ & $d f$ & $E_{\mathrm{O}}$ & $R_{13}$ & $R_{25}$ & Sol. & Starch \\
\hline Between subject effects & & & & & & & \\
Block & 2 & 13 & 0.89 & 0.05 & 0.12 & 0.32 & 0.26 \\
Temp. (TC) & 1 & 13 & $\mathbf{0 . 0 0 2}$ & $\mathbf{0 . 0 3}$ & $<\mathbf{0 . 0 0 0 1}$ & $\mathbf{0 . 0 2}$ & $\mathbf{0 . 0 3}$ \\
Light (L) & 1 & 13 & $\mathbf{0 . 0 0 0 4}$ & $\mathbf{0 . 0 0 2}$ & $<\mathbf{0 . 0 0 0 1}$ & $\mathbf{0 . 0 1}$ & 0.06 \\
Fert. (F) & 1 & 13 & 0.65 & 0.42 & 0.21 & $<\mathbf{0 . 0 0 0 1}$ & $\mathbf{0 . 0 1}$ \\
TC $\times$ L & 1 & 13 & 0.38 & 0.06 & $\mathbf{0 . 0 0 2}$ & 0.63 & 0.21 \\
TC $\times$ F & 1 & 13 & 0.85 & 0.83 & 0.28 & 0.11 & $\mathbf{0 . 0 1}$ \\
L $\times$ F & 1 & 13 & 0.20 & 0.31 & $\mathbf{0 . 0 4}$ & 0.84 & 0.09 \\
TC $\times$ L $\times$ F & 1 & 13 & 0.36 & $\mathbf{0 . 0 5}$ & 0.11 & 0.45 & 0.71 \\
\hline Within subject effects & & & & & & 0.93 \\
Time & 2 & 30 & 0.61 & 0.40 & 0.37 & 0.61 & 0.51 \\
TC $\times$ time & 2 & 30 & 0.49 & 0.21 & 0.94 & 0.96 & 0.53 \\
L $\times$ time & 2 & 30 & 0.75 & 0.19 & 0.12 & 0.59 & 0.53 \\
F $\times$ time & 2 & 30 & 0.85 & 0.87 & 0.60 & 0.99 & 0.12 \\
TC $\times$ L $\times$ time & 2 & 30 & 0.23 & 0.76 & 0.20 & 0.59 & 0.68 \\
TC $\times$ F $\times$ time & 2 & 30 & 0.97 & 0.77 & 0.94 & 0.89 & 0.97 \\
L $\times$ F $\times$ time & 2 & 30 & 0.83 & 0.31 & 0.32 & 0.92 & 0.26 \\
\hline
\end{tabular}

3.6. Relationships among Respiration Parameters and Associated Leaf Traits. $R_{13}$ was not correlated with leaf $[N]$ under any treatment combination with the exception of "cool" grown plants under HL which was only marginally significant $\left(r^{2}=0.29 ; P=0.07\right.$; Figure $\left.3(\mathrm{a})\right)$. No relationship was evident between leaf $[N]$ and $R_{25}$ or $E_{\mathrm{O}}$ (data not shown). $R_{25}$ was significantly correlated with leaf starch across treatments in both "warm" and "cool" grown plants $\left(r^{2}=0.46\right.$; $P=0.008$ and $r^{2}=0.29 ; P=0.01$, respectively; Figure 4). However, within the cold grown plants the low light, fertilization treatment was anomalous and was left out of the regression analysis (Figure 4(a)). Analysis of covariance (ANACOVA) showed a slightly significant $(P=0.10)$ difference in the relationship (slopes) among our treatments.

\section{Discussion}

Accurately accounting for thermal acclimation in carbon cycle models can have a profound effect on annual respiration estimates $[34,35,36]$. Given that studies which report on the presence or absence of thermal respiratory acclimation are often contradictory, for example, $[6,7,10,11,14,18$, $19,24,37-44]$, our study is unique in that it was designed to manipulate precursors for warm, i.e., carbohydrates, [19] and cool respiration, i.e., leaf $[N][11,19,43,45-49]$, in order to analyse the mechanistic underpinnings of the temperature response of respiration $\left(E_{\mathrm{O}}\right)$, warm respiration $\left(R_{25}\right.$ in our case), and cool respiration ( $R_{13}$ in our case). This was done in an attempt to help explain why these contradictory results in published findings of acclimation, or lack thereof, exist.

Our results, however, only partially supported our hypotheses in that we did observe respiratory acclimation, and this acclimation did result from a decrease in $E_{O}$ with increasing growth temperature, as expected. Interestingly, these acclimatory responses were only evident in plants grown with no light or nutrition manipulations, indicating that plants growing in less than ideal situations (LL and NF) may be incapable of acclimating to increased temperatures. It was also apparent that this lack of acclimation in our LL, NF combinations were much stronger when two manipulations were combined as opposed to just one (i.e., either light or nutrition). It appears that light controlled these acclimatory responses much more strongly than nutrition evidenced by the fact that the HL,NF plants were still capable of thermal respiratory acclimation while the LL,F plants showed no evidence of acclimation. We observed no overall change in $R_{13}$ with changes in growth temperature with very few exceptions across treatments. This was not expected due to the strong previously published relationships between cool respiration and leaf $[N]$ $[2,19,28]$, but we did not observe a change in $R_{13}$ which is indicative of Type I acclimation as defined by Atkin and Tjoelker [4].

Because of the suggested link between leaf respiration rates and mitochondrial substrate supply, i.e., carbohydrates; $[20,50]$, we also hypothesized that we would observe a decline in both $E_{\mathrm{O}}$ and $R_{25}$ throughout the night due to a depletion of leaf carbohydrate and that this decline would be much more pronounced in the warm grown plants. Previous reports have indicated that as much as a $50 \%$ decline in leaf starch can occur throughout a 12-hour dark period [51]. Surprisingly, we observed no discernible change in any of our respiration parameters or carbohydrate concentrations throughout the night. This stability of both the temperature response and warm respiration may be in part due to the stability of leaf carbohydrate concentrations.

We did observe a decline in $E_{\mathrm{O}}$ and $R_{25}$ in the "low-light" (LL) treatments, regardless of fertilization, but this was not a function of leaf carbohydrate status. We found a slight increase in leaf nonstructural C (starch and soluble sugars) 


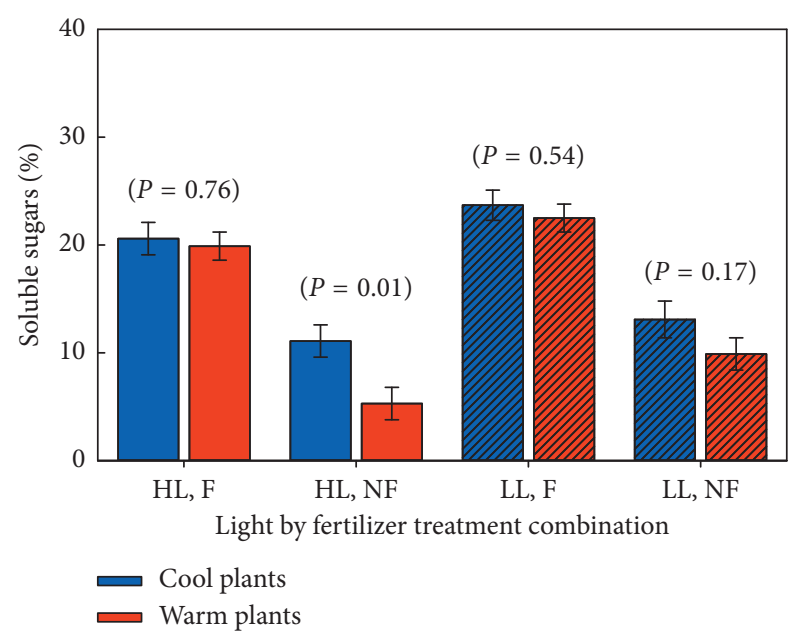

(a)

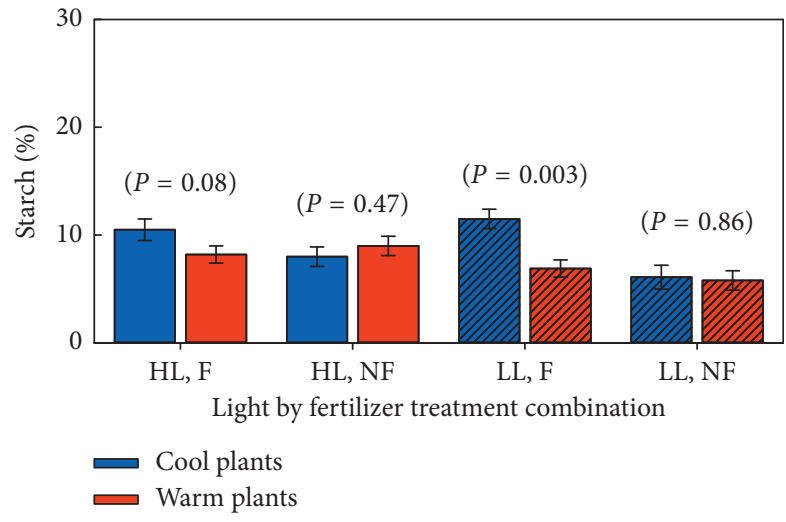

(b)

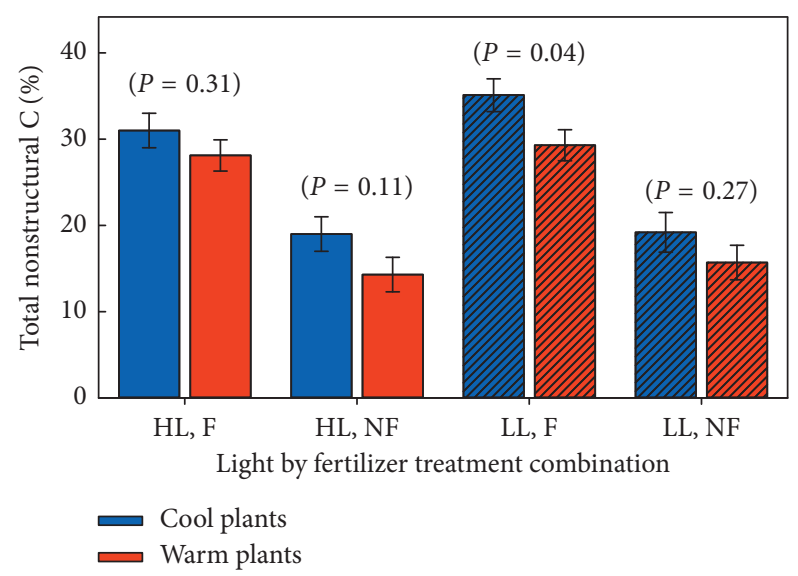

(c)

Figure 2: Differences among resource manipulation treatments for "warm" and "cool” grown plants (red and blue bars, respectively) for percent soluble sugars (a), starch (b), and total nonstructural C (c). Bars represent least square means $(n=18)$ throughout the night (error bars represent \pm one standard error from the mean). $P$ values show comparisons among "warm" and "cool" grown plants for each light (high light $=\mathrm{HL}$ and low light $=\mathrm{LL})$ by fertilization $(\mathrm{F}=$ fertilized and $\mathrm{NF}=$ no fertilizer added $)$ treatment combinations.

TABLE 2: Leaf attributes of Glysine max (soybean) plants exposed to different combinations of light and fertilization grown under "warm" $\left(30^{\circ} / 23^{\circ} \mathrm{C}\right.$ day $/$ night $)$ and "cool" $\left(20^{\circ} / 13^{\circ} \mathrm{C}\right.$ day/night $)$ temperature treatments.

\begin{tabular}{lcccc}
\hline Leaf attributes & Light,Fert & Warm & Cool & $P$ value \\
\hline & HL,NF & $418 \pm 6$ & $417 \pm 2$ & 0.96 \\
Mass-based leaf & HL,F & $425 \pm 8$ & $422 \pm 10$ & 0.87 \\
C $\left(\mathrm{mg} \cdot \mathrm{g}^{-1}\right)$ & LL,NF & $394 \pm 42$ & $423 \pm 7$ & 0.20 \\
& LL,F & $413 \pm 4$ & $416 \pm 4$ & 0.87 \\
\hline & HL,NF & $38 \pm 3$ & $47 \pm 2$ & $\mathbf{0 . 0 4}$ \\
Mass-based leaf $^{-1}$ & HL,F & $59 \pm 2$ & $59 \pm 3$ & 1.00 \\
N (mg.g $\left.{ }^{-1}\right)$ & LL,NF & $45 \pm 5$ & $56 \pm 2$ & $\mathbf{0 . 0 1}$ \\
& LL,F & $63 \pm 2$ & $65 \pm 2$ & 0.63 \\
\hline & HL,NF & $1.48 \pm 0.11$ & $1.57 \pm 1.10$ & 0.74 \\
Area-based leaf & HL,F & $2.18 \pm 0.16$ & $2.03 \pm 0.19$ & 0.66 \\
N (g.cm $\left.{ }^{-2}\right)$ & LL,NF & $2.11 \pm 0.22$ & $2.25 \pm 0.19$ & 0.61 \\
& LL,F & $2.94 \pm 0.28$ & $2.63 \pm 0.14$ & 0.25 \\
\hline & HL,NF & $39.5 \pm 2.7$ & $33.8 \pm 1.9$ & 0.11 \\
SLA $\left(\mathrm{g} \cdot \mathrm{cm}^{-2}\right)$ & HL,F & $36.9 \pm 2.4$ & $34.2 \pm 1.9$ & 0.48 \\
& LL,NF & $46.9 \pm 2.2$ & $40.0 \pm 1.6$ & 0.06 \\
& LL,F & $46.3 \pm 3.9$ & $40.3 \pm 2.4$ & 0.10 \\
\hline
\end{tabular}

in our low-light treatments, which is likely a function of reduced $\mathrm{C}$ use throughout the day as a result of the shade treatment. Both "warm" and "cool" grown plants across treatments showed a strong positive correlation between leaf starch and $R_{25}$. Within the "cool" grown plants, however, the LL,F treatment was considered an outlier and was not included in the regression analysis (Figure 4; circled observations). We hypothesize that the reasoning behind this anomalous treatment is that even though starch is likely a source of energy for the enzymatic reactions associated with leaf $R_{\mathrm{D}}$, the starch concentration in a leaf is not affected by simply one day of reduced photosynthesis as designed in this experiment, and due to the decrease in photosynthetic rate, there was a drastic reduction in respiration rate indicating a direct link between photosynthesis and respiration, possibly through a decline in ATPconsumption rates [20]. This link between these two associated metabolic processes has been shown in numerous studies [11, 14, 19, 37, 52-57]. It is equally as likely that this same phenomenon was not observed in the warm grown plants due to the increased demand for substrate because of 


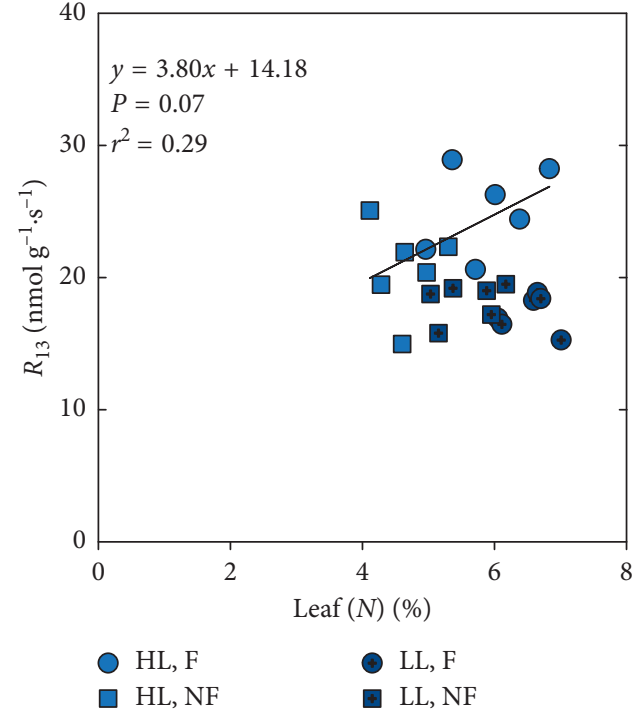

(a)

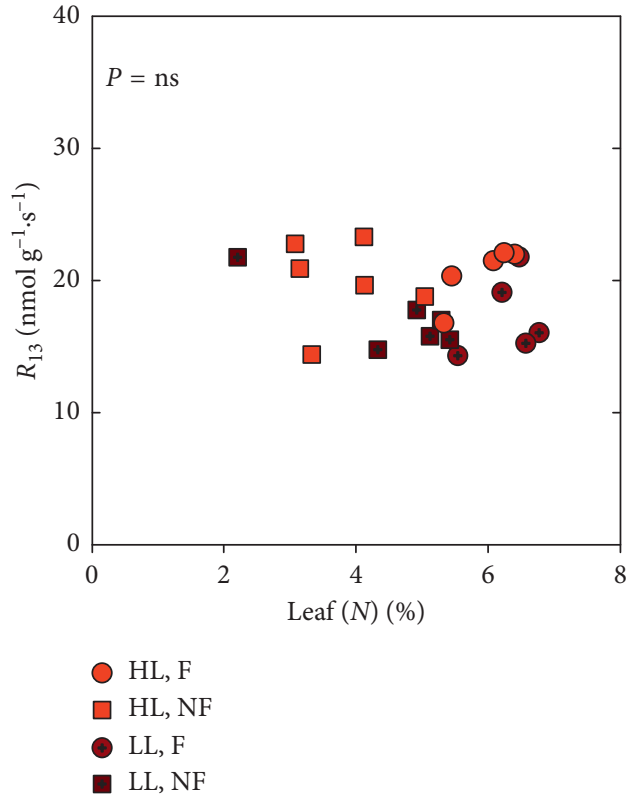

(b)

FigURE 3: Relationship between cool respiration $\left(R_{13}\right)$ and percent leaf $N$ concentration $([N])$ for "cool" and "warm" grown plants (represented in (a) and (b) and shown using blue and red symbols, respectively). Regressions were performed across fertilization (F,NF) treatments within a light (HL,LL) treatment.

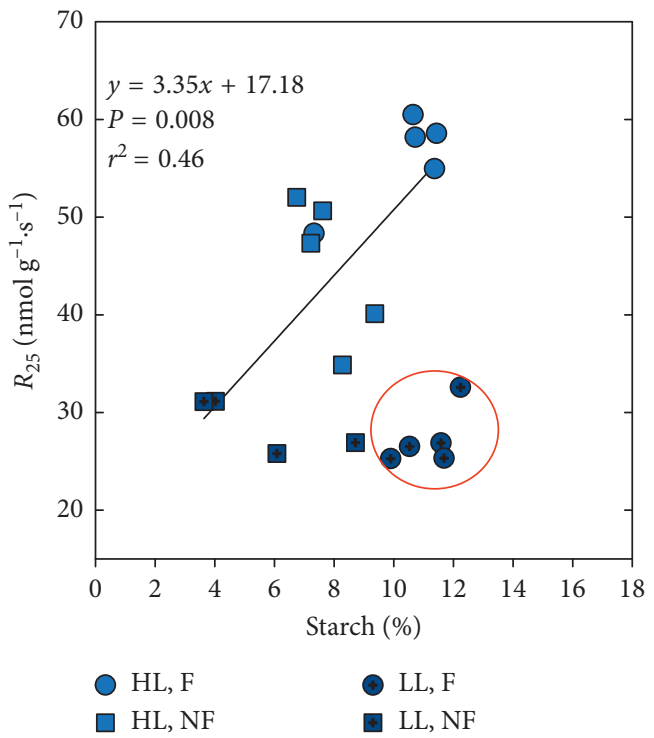

(a)

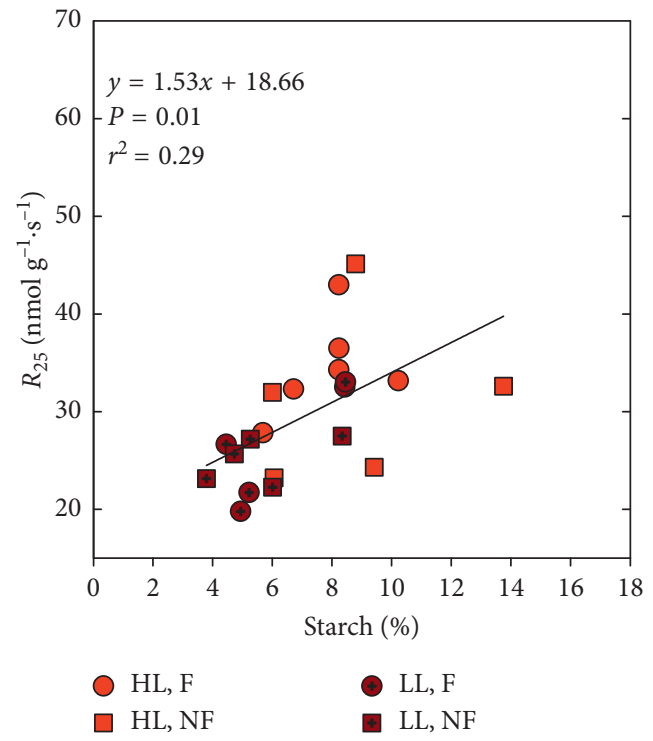

(b)

Figure 4: Relationship between warm respiration $\left(R_{25}\right)$ and percent leaf starch for "cool" and "warm" grown plants (represented in (a) and (b) and shown using blue and red symbols, respectively). Regressions were performed across all treatments combined. Circled observation in (a) indicates omission of the low light, fertilized (LL,F) treatment from regression analyses.

the $10^{\circ} \mathrm{C}$ increase in night temperature associated with the "warm" treatment. Utilizing light response curves for soybean from Lauer et al. [57] and measuring $A_{\text {Sat }}$ rates on HL plants (data not shown), we estimate that our LL plants experienced an approximately $60 \%$ reduction in photosynthetic rates as a result of our shade treatments (i.e., $30 \%$ of full sunlight). This estimate reasonably assumes that the short duration of the LL treatment (1 day) would not be enough time to impact leaf photochemical efficiency (slope) or the light saturation. Even with this substantial decrease in photosynthesis, starch and especially soluble carbohydrate concentrations in fertilized plants remained drastically higher than their NF counterparts in the "cool" treatment. 
While the plants in our study were clearly not "starved" for nitrogen (even within the nonfertilized treatment based upon leaf $N$ values of $3.8-5 \%$ ), we did increase leaf $[N]$ significantly with our fertilization treatment. We did observe shifts in allocation which are indicative of a nitrogen limitation. Ruffy et al. [58] suggested that nitrogen limitations can cause a general decline in the plants carbohydrate utilization efficiency which ultimately would result in a shift of allocation from roots to shoots. As reported in Ruffy et al. [58], we also observed a $22 \%$ increase in the shoot to root ratio although this was only marginally significant between fertilized and unfertilized plants $(P=0.09)$. It is important that more studies be conducted with more drastic nitrogen limitations imposed to tease out the mechanistic underpinnings of nutrient limitations on thermal acclimation of leaf dark respiration.

\section{Conclusions}

If the results of this study translate into similar findings in field situations and similar trends were to be found in photosynthetic acclimatory responses to stressors, this study has far-reaching implications for both managed and unmanaged (natural) landscapes. If plants are unable to acclimate metabolically to increased temperatures when grown in lower nutrition or low light (or a combination of these situations), agricultural (managed) and natural ecosystems which have these characteristics may be much more susceptible to current and future temperature increases associated with climate change. This limitation hypothesis which would potentially allow natural and managed ecosystems to be classified as to their potential resiliency to climate change needs to be thoroughly addressed in future studies.

\section{Data Availability}

The data used to support the findings of this study are available from the corresponding author upon request.

\section{Disclosure}

This work was presented as a poster and abstract at the 98th Ecological Society of America Annual Meeting, Minneapolis, MN (August 2013).

\section{Conflicts of Interest}

The authors declare that there are no conflicts of interest regarding the publication of this paper.

\section{Acknowledgments}

The authors would like to thank Jessica LaGrone for her assistance with data collection and Roxie A. Jordan, Greenhouse Lab Supervisor, Louisiana Tech Department of Agriculture, for providing greenhouse space and technical support. This work was supported by National Science Foundation (NSF), EPSCoR Pilot funding program (grant number NSF(2010)-PFUND-200), and McIntire-Stennis formula funding (grant no. LAZ00074).

\section{References}

[1] J. S. Amthor, "The Mcree-de Wit-Penning Vries-Thornley respiration paradigms: 30 years later," Annnals of Botany, vol. 86 , no. 1 , pp. $1-20,2000$.

[2] M. G. Ryan, "Effects of climate change on plant respiration," Ecological Applications, vol. 1, no. 2, pp. 157-167, 1991.

[3] R. C. Dewar, B. E. Medlyn, and R. E. McMurtrie, "Acclimation of the respiration/photosynthesis ratio to temperature: insights from a model," Global Change Biology, vol. 5, no. 5, pp. 615-622, 1999.

[4] O. K. Atkin and M. G. Tjoelker, "Thermal acclimation and the dynamic response of plant respiration to temperature," Trends in Plant Science, vol. 8, no. 7, pp. 343-351, 2003.

[5] A. F. Armstrong, D. C. Logan, and O. K. Atkin, "On the developmental dependence of leaf respiration: responses to short- and long-term changes in growth temperature," Annals of Botany, vol. 93, no. 11, pp. 1633-1639, 2006.

[6] J. M. Frantz, N. N. Cornetti, and B. G. Bugbee, "Night temperature has a minimal effect on respiration and growth in rapidly growing plants," Annals of Botany, vol. 94, no. 1, pp. 155-166, 2004.

[7] O. K. Atkin, I. Scheurwater, and T. L. Pons, "High thermal acclimation of both photosynthesis and respiration in two lowland Plantago species in contrast to an alpine congeneric," Global Change Biology, vol. 12, no. 3, pp. 500-515, 2006.

[8] J. A. Arnone and C. Korner, "Temperature adaptation and acclimation potential of leaf dark respiration in two species of ranunculus in warm and cold habitats," Arctic and Alpine Research, vol. 29, no. 1, pp. 122-125, 1997.

[9] A. Larigauderie and C. Korner, "Acclimation of leaf dark respiration to temperature in alpine and lowland plant species," Annals of Botany, vol. 76, no. 3, pp. 245-252, 1995.

[10] M. G. Tjoelker, J. Oleksyn, and P. B. Reich, "Acclimation of respiration to temperature and $\mathrm{CO}_{2}$ in seedlings of boreal tree species in relation to plant size and relative growth rate," Global Change Biology, vol. 5, no. 6, pp. 679-691, 1999.

[11] I. J. Wright, P. B. Reich, O. K. Atkin, C. H. Lusk, M. G. Tjoelker, and M. Westoby, "Irradiance, temperature and rainfall influence leaf dark respiration in woody plants: evidence from comparisons across 20 sites," New Phytologist, vol. 169, no. 2, pp. 309-319, 2005.

[12] L. H. Ziska and J. A. Bunce, "Direct and indirect inhibition of single leaf respiration by elevated $\mathrm{CO} 2$ concentrations: interaction with temperature," Physiologia Plantarum, vol. 90, no. 1, pp. 130-138, 1994.

[13] D. Bruhn, M. Schortemeyer, E. J. Edwards et al., "The apparent temperature response of leaf respiration depends on the timescale of measurements: a study of two cold climate species," Plant Biology, vol. 10, no. 2, pp. 185-193, 2008.

[14] B. R. Loveys, L. J. Atkinson, D. J. Sherlock, R. L. Roberts, A. H. Fitter, and O. K. Atkin, "Thermal acclimation of leaf and root respiration: and investigation comparing inherently fastand slow-growing plant species," Global Change Biology, vol. 9, no. 6, pp. 895-910, 2003.

[15] M. G. Tjoelker, J. Oleksyn, and P. B. Reich, "Modelling respiration of vegetation: evidence for a general temperaturedependence $\mathrm{Q}_{10}$," Global Change Biology, vol. 7, no. 2, pp. 223-230, 2001.

[16] J. Lloyd and J. A. Taylor, "On the temperature-dependence of soil respiration," Functional Ecology, vol. 8, no. 3, pp. 315-323, 1994.

[17] O. K. Atkin, D. Bruhn, V. M. Hurry, and M. G. Tjoelker, “The hot and the cold: unraveling the variable response of plant 
respiration to temperature," Functional Plant Biology, vol. 32, no. 2, pp. 87-105, 2005.

[18] K. L. Griffin, M. Turnbull, R. Murthy et al., "Leaf respiration is differentially affected by leaf vs stand level night-time warming," Global Change Biology, vol. 8, no. 5, pp. 479485, 2002.

[19] D. N. Dillaway and E. L. Kruger, "Leaf respiratory acclimation to climate: comparisons among boreal and temperate tree species along a latitudinal transect," Tree Physiology, vol. 31, no. 10, pp. 1114-1127, 2011.

[20] O. K. Atkin, J. R. Evans, M. C. Ball, H. Lambers, and T. L. Pons, "Leaf respiration of snow gum in the light and dark. Interactions between irradiance and temperature," Plant Physiology, vol. 122, no. 3, pp. 915-922, 2000.

[21] O. K. Atkin, I. Scheurwater, and T. L. Pons, "Respiration as a percentage of daily photosynthesis in whole plants is homeostatic at moderate, but not high, growth temperatures," New Phytologist, vol. 174, no. 2, pp. 367-380, 2007.

[22] K. A. Mitchell, P. V. Bolstad, and J. M. Vose, "Interspecific and environmentally induced variation in foliar dark respiration among eighteen southeastern deciduous tree species," Tree Physiology, vol. 19, no. 13, pp. 861-870, 1999.

[23] P. B. Reich, M. B. Walters, M. G. Tjoelker, D. Vanderklein, and C. Buschena, "Photosynthesis and respiration rates depend on leaf and root morphology and nitrogen concentration in nine boreal tree species differing in relative growth rate," Functional Ecology, vol. 12, no. 3, pp. 395-405, 1998.

[24] M. G. Tjoelker, J. Oleksyn, P. B. Reich, and R. Żytkowiak, "Coupling of respiration, nitrogen, and sugars underlies convergent temperature acclimation in Pinus banksiana across wide-ranging sites and populations," Global Change Biology, vol. 14, no. 4, pp. 1-16, 2008.

[25] M. G. Tjoelker, J. Oleksyn, G. Lorenc-Plucinska, and P. B. Reich, "Acclimation of respiratory temperature responses in northern and southern populations of Pinus Banksiana," New Phytologist, vol. 181, no. 1, pp. 218-229, 2009.

[26] I. Florez-Sarasa, W. L. Araújo, S. V. Wallström, A. G. Rasmusson, A. R. Fernie, and M. Ribas-Carbo, "Lightresponsive metabolite and transcript levels are maintained following a dark-adaptation period in leaves of Arabidopsis thaliana," New Phytologist, vol. 195, no. 1, pp. 136-148, 2012.

[27] J. Azcon-Bieto and C. B. Osmond, "Relationship between photosynthesis and respiration: the effect of carbohydrate status on the rate of $\mathrm{CO} 2$ production by respiration in darkened and illuminated wheat leaves," Plant Physiology, vol. 71, no. 3, pp. 574-581, 1983.

[28] M. Turnbull, D. Whitehead, D. T. Tissue, W. S. F. Schuster, K. J. Brown, and K. L. Griffin, "Responses of leaf respiration to temperature and leaf characteristics in three deciduous tree species vary with site water availability," Tree Physiology, vol. 21, no. 9, pp. 571-578, 2001

[29] K. Y. Crous, G. Wallin, O. K. Atkin, J. Uddling, and A. af Ekenstam, "Acclimation of light and dark respiration to experimental and seasonal warming are mediated by changes in leaf nitrogen in Eucalyptus globulus," Tree Physiology, vol. 37, no. 8, pp. 1069-1083, 2017.

[30] L. F. Ow, K. L. Griffin, D. Whitehead, A. S. Walcroft, and M. H. Turnbull, "Thermal acclimation of leaf respiration but not photosynthesis in Populus deltoides x nigra," New Phytologist, vol. 178, no. 1, pp. 123-134, 2008.

[31] T. L. Pons and R. M. Welschen, "Over estimation of respiration rates in commercially available clamp-on leaf chambers. Complications with measurements of net photosynthesis,"
Plant Cell and Environment, vol. 25, no. 10, pp. 1367-1372, 2002.

[32] C. M. Kaelke, E. L. Kruger, and P. B. Reich, "Trade-offs in seedling survival, growth and physiology among hardwood species of contrasting successional status along a light availability gradient," Canadian Journal of Forest Research, vol. 31, no. 9, pp. 1602-1616, 2001.

[33] SAS, SAS/STAT ${ }^{\circledR} 12.1$ User's Guide, SAS Institute Inc., Cary, NC, USA, 2012.

[34] N. G. Smith and J. S. Dukes, "Plant respiration and photosynthesis in global-scale models: incorporating acclimation to temperature and CO2," Global Change Biology, vol. 19, no. 1, pp. 45-63, 2013.

[35] M. C. Vanderwel, M. Slot, J. W. Lichstein et al., "Global convergence in leaf respiration from estimates of thermal acclimation across time and space," New Phytologist, vol. 207, no. 4, pp. 1026-1037, 2015.

[36] O. K. Atkin, K. J. Bloomfield, P. B. Reich et al., "Global variability in leaf respiration in relation to climate, plant functional types and leaf traits," New Phytologist, vol. 206, no. 2, pp. 614-636, 2015.

[37] J. Zaragoza-Castells, D. Sánchez-Gómez, I. P. Hartley et al., "Climate-dependent variations in leaf respiration in a dryland, low productivity Mediterranean forest: the importance of acclimation in both high-light and shaded habitats," Functional Ecology, vol. 22, pp. 172-184, 2008.

[38] W. Yamori, K. Noguchi, K. Hikosaka, and I. Terashima, "Cold-tolerant crop species have greater temperature homeostasis of leaf respiration and photosynthesis than coldsensitive species," Plant and Cell Physiology, vol. 50, no. 2, pp. 203-215, 2008.

[39] L. F. Ow, D. Whitehead, A. S. Walcroft, and M. H. Turnbul, "Seasonal variation in foliar carbon exhchange in Pinus radiata and Populus deltoides: respiration acclimates fully to changes in temperature but photosynthesis does not," Global Change Biology, vol. 16, no. 1, pp. 288-302, 2010.

[40] D. A. Way and R. Oren, "Differential responses to changes in growth temperature between trees from different functional groups and biomes: a review and synthesis of data," Tree Physiology, vol. 30, no. 6, pp. 669-688, 2010.

[41] J. Rodriguz-Calceradda, O. K. Atkin, T. M. Robson, J. Zaragoza-Castells, L. Gil, and I. Aranda, "Thermal acclimation of leaf dark respiration of beech seedlings experiencing summer drought in high and low light environments," Tree Physiology, vol. 30, no. 2, pp. 214-224, 2010.

[42] A. Laragauderie and C. Korner, "Acclimation of leaf dark respiration to temperature in alpine and lowland plant species,” Annals of Botany, vol. 76, no. 3, pp. 245-252, 1995.

[43] T. D. Lee, P. B. Reich, and P. V. Bolstad, "Acclimation of leaf respiration to temperature is rapid and related to specific leaf area, soluble sugars and leaf nitrogen across three temperature deciduous tree species," Functional Ecology, vol. 19, no. 4, pp. 640-647, 2005.

[44] P. V. Bolstad, A. K. Mitchell, and J. M. Vose, "Foliar temperature-respiration response functions for broad-leaved tree species in the southern Appalachians," Tree Physiology, vol. 19, no. 13, pp. 871-878, 1999.

[45] M. G. Ryan, "Foliar maintenance respiration of subalpine and boreal trees and shrubs in relation to nitrogen content," Plant Cell and Environment, vol. 18, no. 7, pp. 765-772, 1995.

[46] M. G. Tjoelker, P. B. Reich, and J. Oleksyn, "Changes in leaf nitrogen and carbohydrates underlie temperature and $\mathrm{CO}_{2}$ acclimation of dark respiration in five boreal tree species," Plant Cell and Environment, vol. 22, no. 7, pp. 767-778, 1999. 
[47] M. Turnbull, D. Whitehead, D. T. Tissue, W. S. F. Schuster, K. J. Brown, and K. L. Griffin, "Scaling foliar respiration in two contrasting forest canopies," Functional Ecology, vol. 17, no. 1, pp. 101-114, 2003.

[48] P. B. Reich, J. Oleksyn, and M. G. Tjoelker, "Needle respiration and nitrogen concentration in Scots pine populations from a broad latitudinal range: a common garden test with field grown trees," Functional Ecology, vol. 10, no. 6, pp. 768-776, 1996.

[49] P. B. Reich, M. G. Tjoelker, K. S. Pregitzer, I. J. Wright, J. Oleksyn, and J.-L. Machado, "Scaling of respiration to nitrogen in leaves, stems and roots in higher land plants," Ecology Letters, vol. 11, no. 8, pp. 793-801, 2008.

[50] O. K. Atkin and H. lambers, "Slow-growing alpine and fast growing lowland species: a case study of factors associated with variation in growth rate among herbaceous higher plants under natural and controlled conditions," in Inherent Variation in Plant Growth: Physiological Mechanisms and Ecological Consequences, $\mathrm{H}$. lambers, $\mathrm{H}$. Poorter, and M. M. I. Van Vuuren, Eds., pp. 259-288, Backhuys Publishers, Leiden, Netherlands, 1998.

[51] V. L. Lechtenberg, D. A. Holt, and H. W. Youngberg, "Diurnal variation in nonstructural carbohydrates, in vitro digestibility, and leaf to stem ratio of alfalfa," Agronomy Journal, vol. 63, no. 5, pp. 719-724, 1971

[52] J. A. Bunce, "Direct and acclimatory responses of dark respiration and translocation to temperature," Annals of Botany, vol. 100, no. 1, pp. 67-73, 2007.

[53] I. P. Hartley, A. F. Armstrong, R. Murthy, G. Barron-Gafford, P. Ineson, and O. K. Atkin, "The dependence of respiration on photosynthetic substrate supply and temperature: integrating leaf, soil and ecosystem measurements," Global Change Biology, vol. 12, no. 10, pp. 1954-1968, 2006.

[54] K. Maseyk, J. M. Grünzweig, E. Rotenberg, and D. Yakir, "Respiration acclimation contributes to high carbon-use efficiency in a seasonally dry pine forest," Global Change Biology, vol. 14, no. 7, pp. 1553-1567, 2008.

[55] T. M. Wertin and R. O. Teskey, "Close coupling of wholeplant respiration to net photosynthesis and carbohydrates," Tree Physiology, vol. 28, pp. 1831-1840, 2008.

[56] D. Whitehead, K. L. Griffin, M. H. Turnbull et al., "Response of total night-time respiration to differences in total daily photosynthesis for leaves in a Quercus rubra L. canopy: implications for modelling canopy $\mathrm{CO}_{2}$ exchange," Global Change Biology, vol. 10, pp. 925-938, 2004.

[57] M. J. Lauer, S. G. Pallardy, D. G. Blevins, and D. D. Randall, "Whole leaf carbon exchange characteristics of phosphate deficient soybeans (Glycine max L.)," Plant Physiology, vol. 91, pp. 848-854, 1989.

[58] T. W. Ruffy, S. C. Huber, and R. J. Volk, "Alterations in leaf carbohydrate metabolism in response to nitrogen stress," Plant Physiology, vol. 88, pp. 725-730, 1988. 


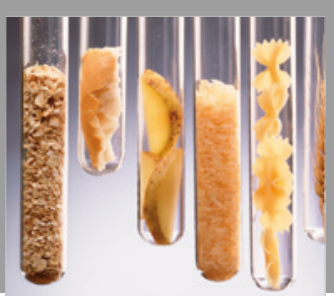

International Journal of Food Science

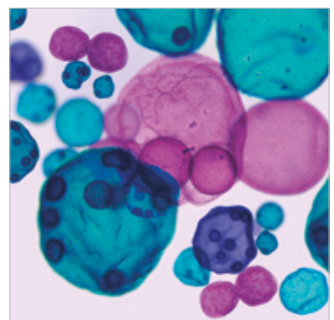

International Journal of Microbiology
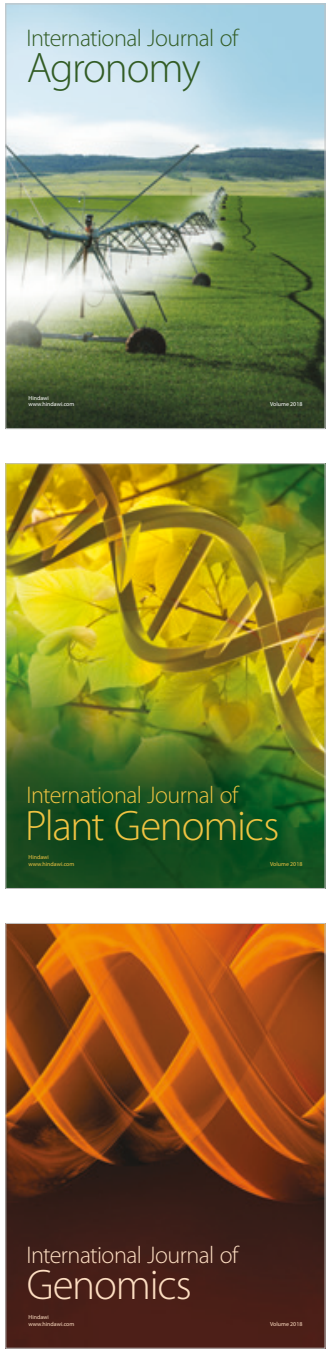

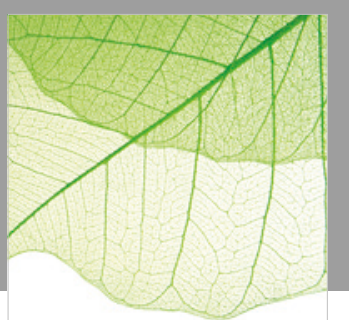

Journal of Botany
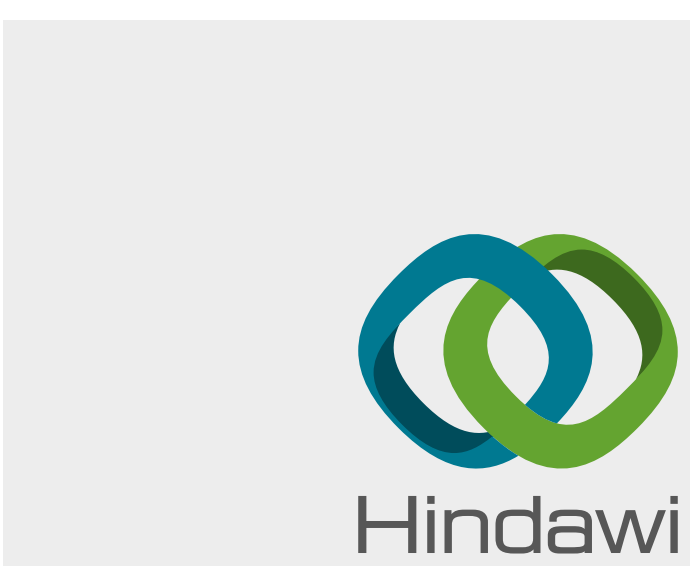

Submit your manuscripts at

www.hindawi.com
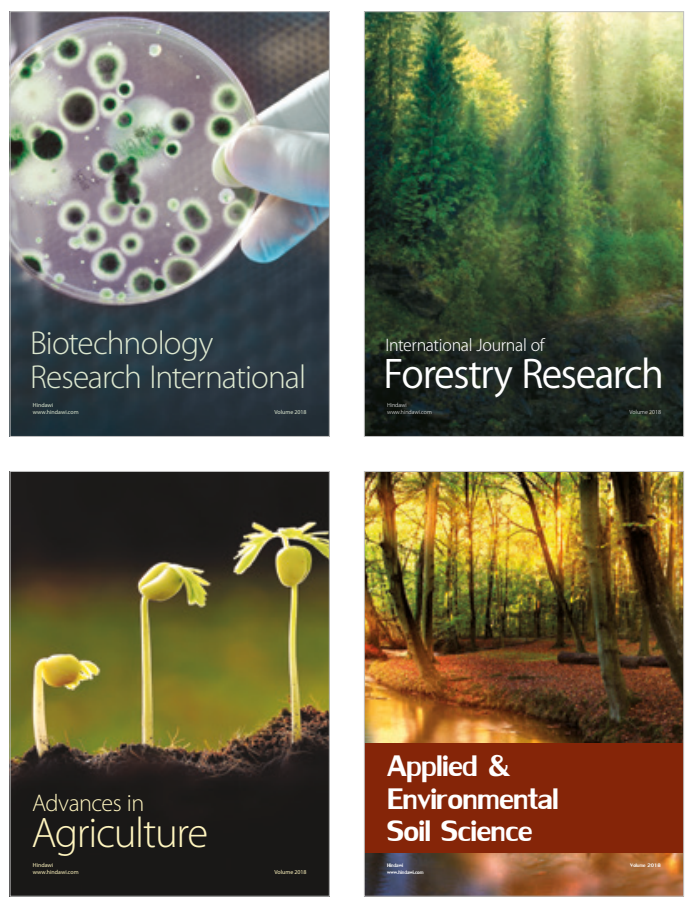

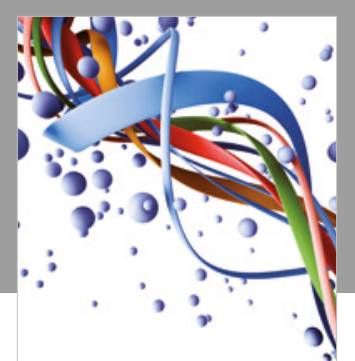

Scientifica

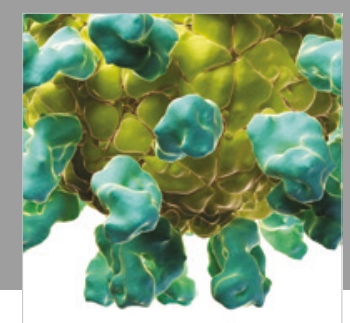

Veterinary Medicine International

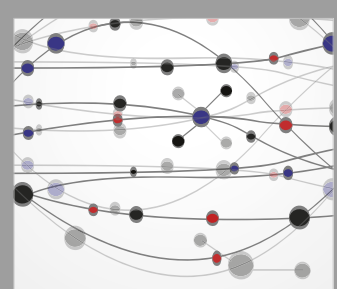

The Scientific World Journal
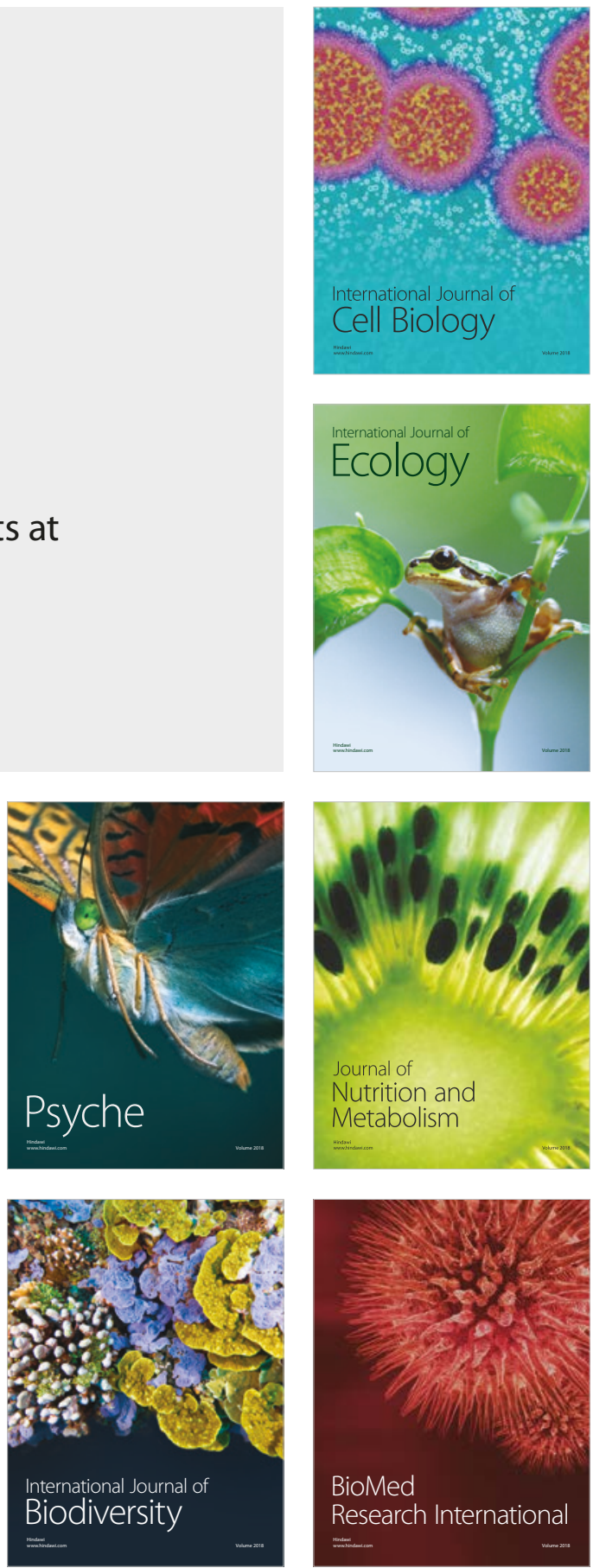